\title{
Evaluation of Commercial Immunochromatographic Test Kits for the Detection of Canine Distemper Virus
}

\author{
Dong-Kun Yang ${ }^{*}$, Ha-Hyun Kim, Jienny Lee, Miryeon Ji, Subin Oh, Hyang-Sim Lee, Bang-Hun Hyun \\ Viral Disease Research Division, Animal and Plant Quarantine Agency, MAFRA, Gimcheon 39660, Republic of Korea
}

\author{
Corresponding \\ Dong-Kun Yang, Ph D, DVM \\ Animal and Plant Quarantine Agency, \\ 177 Hyeoksin 8-ro, Gimcheon-si, \\ Gyeongsangbuk-do 39660, Republic of \\ Korea \\ Phone : +82-54-912-0785 \\ Fax : +82-54-912-0812 \\ E-mail : yangdk@korea.kr
}

Received : January 1, 2020

Revised : May 31, 2020

Accepted : June 1, 2020

No potential conflict of interest relevant to this article was reported.

Copyright (C) 2020 Journal of Bacteriology and Virology

(C) This is an Open Access article distributed under the terms of the Creative Commons Attribution Non-Commercial License

(http://creativecommons.org/ license/by-nc/3.0/).
The rapid diagnosis of canine distemper virus (CDV) helps to determine the treatment of dogs in veterinary clinics. We evaluated the performance of seven commercial rapid immunochromatographic test (RICT) kits for the detection of CDV. Six core dog viral pathogens (canine adenovirus type 1 and 2, canine coronavirus, canine parainfluenza virus, canine parvovirus, and rabies virus), five CDV strains (CD1901, Lederle, Rockborn, Onderstepoort, and Synder Hill), and three bacteria (Bordetella bronchiseptica, Leptospira canicola, and Staphylococus aureus) were used to determine the cross-reactivity and detection limits of the kits. The seven commercial RICT kits did not yield positive results with the six dog viruses or the three bacteria. All the RICT kits for CDV detected the Korean CDV isolate. The detection limits of the RICT kits for the Korean CDV isolate, CD1901, belonging to Asia 1 genotype ranged from $10^{3.0}$ to $10^{4.0} \mathrm{TCID}_{50} / \mathrm{mL}$. There was an average difference of 1.1 in scores judged by eye between four CDV vaccine strains and CD1901 strain. Therefore, the RICT kits enable the detection of CDV vaccine strains, but need to be improved to detect CDV circulating in dog populations in Korea.

Key Words: Canine distemper virus, Chromatography, Diagnosis

\section{INTRODUCTION}

Canine distemper (CD) is a fatal viral disease of dogs and wildlife such as raccoons, tigers, lions, brown hyena, panda, and monkey $(1,2)$, and is serious and frequently fatal. CD is caused by canine distemper virus (CDV), a member of the genus Morbillivirus of the family Paramyxoviridae that has a non-segmented negative single-stranded RNA genome. The CDV genome encodes eight viral proteins named as nucleocapsid $(N)$, phosphoprotein $(P)$, non-structural proteins $(V$ and $C)$, matrix $(M)$, Fusion $(F)$, hemagglutinin $(H)$, and polymerase (L). Two glycoproteins ( $\mathrm{F}$ and $\mathrm{H}$ ) are responsible for viral attachment, entry and membrane fusion $(1,3)$. Among eight viral proteins, $H$ protein of CDV has the greatest genetic variation. Based on the homology of $\mathrm{H}$ gene, $\mathrm{CDV}$ has been classified into at least seven genotypes: America 1, America 2, Europe, Europe wildlife, Arctic, Asia 1 and Asia 2. Various CDV genotypes have been identified in recent isolates from dogs, despite the existence of only one serotype (3-5).

Dogs infected with CDV show various clinical symptoms such as skin pustules, hyperkeratosis, fever, coughing, diarrhea and more than $80 \%$ of dogs with 
neurologic symptoms can be life threatened $(6,7)$. Therefore, the fast and accurate diagnosis of CDV in clinical samples from dogs suspected of being infected with CDV can guide the treatment of animals.

Various laboratory tests are used for the diagnosis of CDV in animals, including virus isolation, indirect immunofluorescence assay, conventional, nested or real-time reverse transcription-polymerase chain reaction (RT-PCR), loop-mediated isothermal amplification, serum neutralization test, enzyme-linked immunosorbent assay, and rapid immunochromatographic test (RICT) (8-12). Among the methods mentioned above, the most sensitive diagnostic test is the RT-PCR technique. Despite being accurate and fast, the procedure of RT-PCR is complex, expensive and difficult to perform in animal clinic. On the other hand, the RICT method is popular in veterinary clinics because of their simplicity and speed using ocular and nasal discharges. RICT kits exploit fluid migration of a sample on a nitrocellulose membrane. The CDV antigen is combined with a gold-conjugated antibody against CDV, and the antigen-antibody complex is immobilized through binding to a second antibody fixed on the membrane. The RICT technique has been applied to a variety of pathogens, including RABV, CPV, and porcine epidemic diarrhea virus $(13,14)$

Recently, a CDV (CD1901 isolate) belonging to the Asia 1 genotype was isolated from a naturally infected dog in Korea (unpublished). Up to date, commercially available RICT kits for CDV were developed to detect the CDV circulating in dog populations, but, these kits have not been evaluated to detect the Korean CDV isolate belonging to Asia 1 genotype. In this study, we evaluated seven commercial RICT kits in terms of the cross-reactivity for canine pathogens and sensitivity for CDV isolated from Korean dog recently.

\section{MATERLAS AND METHODS}

\section{Viruses and bacteria}

One Korean CDV isolate (CD1901) and four CDV vaccine strains (Lederle, Rockborn, Onderstepoort, and Synder Hill) showing viral titer of at least $10^{4.0} \mathrm{TCID} 50 / \mathrm{mL}$ were used in this study. The CD1901 strain was isolated from a naturally infected dog in 2019. Four CDV strains were obtained from commercially available vaccines. Six dog viral pathogens and three bacteria stored in the Animal and Plane Quarantine Agency (APQA, Korea) were used for a cross-reactivity. To assess the cross-reactivity of commercial RICT kits, the viruses such as canine adenovirus (CAV) type 1 (CAV1V strain, 107.0 $\mathrm{TCID}_{50} / \mathrm{mL}$ ), CAV type 2 (APQA1601 strain, $10^{7.0} \mathrm{TCID} \mathrm{D}_{50} / \mathrm{mL}$ ), canine coronavirus (CCV, DS strain $10^{5.5} \mathrm{TCID} \mathrm{D}_{50} / \mathrm{mL}$ ), canine parainfluenza virus (CPIV, D008 strain, $10^{6.0} \mathrm{TCID} 50 / \mathrm{mL}$ ), canine parvovirus (CPV, KV0901 strain, $10^{6.5} \mathrm{TCID} 50 / \mathrm{mL}$ ), and rabies virus (RABV, ERA strain, $10^{7.0} \mathrm{FAID}_{50} / \mathrm{mL}$ ) and the bacteria such as Bordetella bronchiseptica $\left(10^{7.0} \mathrm{CFU} / \mathrm{mL}\right.$ ), Leptospira canicola $\left(10^{6.0} \mathrm{CFU} / \mathrm{mL}\right)$, and, Staphylococus aureus $\left(10^{7.0} \mathrm{CFU} / \mathrm{mL}\right)$ were used.

\section{Rapid immunochromatographic test (RICT) kits}

The following seven commercial RICT kits from Korean manufacturers were tested: ASAN Easy Test Distemper (ASAN Pharm, Anseong, Korea), Anylab Canine Distemper Virus Antigen Test (Zetbiotech, Cheongju, Korea), Bionet CDV Ag Kit (Bionet, Seongnam, Korea), Anigen Rapid CDV Ag Test Kit (BioNote, Hwaseong, Korea), VDRG CDV Ag Rapid Kit (Median Diagnostics, Chuncheon, Korea), CDV/CAV Ag Combo Test (RapiGEN, Gunpo, Korea), and Canine Distemper Virus Test Kit (VetAll, Goyang, Korea).

Seven commercial RICT kits were used according to the manufacturers' instructions. Briefly, viral or bacterial suspensions were blended at a 1:1 ratio with the dilution buffer provided in the kit. Next, $100 \mathrm{ul}$ of the mixture were applied to the sample well. After application of the mixture, it took 5-10 min to determine the result; the appearance of two purple bands, the test and control lines, was considered a positive result. Positive bands were scored by the naked eye as strong, 3; medium, 2; weak, 1 ; very weak, 0.5 ; and negative, 0 . 


\section{Analysis of $\mathrm{H}$ gene}

We carried out genetic analyses based on the full nucleotide and amino acid sequences of $\mathrm{H}$ gene of Korean CDV strain (CD1901, Korea), four CDV vaccine strains and 24 other field CDV strains obtained from the GenBank of National center for biotechnology information (NCBI, Bethesda, MD, USA, http://www.megasoftware.net/). Similarities among the CD1901 and CDV vaccine strains were performed using DNASTAR software (DNASTAR Inc, Madison, Wisconsin, USA). A phylogenic tree based on $\mathrm{H}$ gene was constructed using MEGA v. 7.0.20 software.

\section{RESULTS}

\section{Cross-reactivity and detection limit}

Cross-reactivity testing of the RICT kits was conducted using six viral and three bacterial dog pathogens. The seven commercial RICT kits did not show positive results with six dog viruses (CAV-1, CAV-2, CCV, CPV, CPIV, and RABV) and three bacteria (Bordetella bronchiseptica, Leptospira canicola, and Staphylococus aureus) (Table 1). The detection limits of

Table 1. Cross-reactivity of rapid immunochromatographic test kits for canine distemper virus

\begin{tabular}{cccccccccc}
\hline \multirow{2}{*}{ Company } & \multicolumn{10}{c}{ Microorganism } \\
\cline { 2 - 10 } & CAV-1 $^{*}$ & CAV-2 & CCV & CPV & CPIV & RABV & B.B & L.cani & S. aure \\
\hline A & $0^{* *}$ & 0 & 0 & 0 & 0 & 0 & 0 & 0 & 0 \\
B & 0 & 0 & 0 & 0 & 0 & 0 & 0 & 0 & 0 \\
C & 0 & 0 & 0 & 0 & 0 & 0 & 0 & 0 & 0 \\
D & 0 & 0 & 0 & 0 & 0 & 0 & 0 & 0 & 0 \\
E & 0 & 0 & 0 & 0 & 0 & 0 & 0 & 0 & 0 \\
F & 0 & 0 & 0 & 0 & 0 & 0 & 0 & 0 & 0 \\
G & 0 & 0 & 0 & 0 & 0 & 0 & 0 & 0 & 0 \\
Mean & 0 & 0 & 0 & 0 & 0 & 0 & 0 & 0 & 0 \\
\hline
\end{tabular}

* CAV-1, canine adenovirus type 1, CAV1V strain, $10^{7.0} \mathrm{TCID}_{50} / \mathrm{mL} ; \mathrm{CAV}-2$, canine adenovirus type 2, APQA1601 stain, $10^{7.0}$ $\mathrm{TCID}_{50} / \mathrm{mL}$; CCV, canine coronavirus, DS strain, $10^{5.5} \mathrm{TCID} 50 / \mathrm{mL} ; \mathrm{CPV}$, canine parvovirus, KV0901 strain, $10^{6.5} \mathrm{TCID} 50 / \mathrm{mL} ; C P I V$, canine parainfluenza virus, D008 strain, $10^{6.0} \mathrm{TCID}_{50} / \mathrm{mL}$; RABV, rabies virus, ERA strain, $10^{7.0} \mathrm{FAID}_{50} / \mathrm{mL} ;$ B. bron, Bordetella bronchiseptica, $10^{7.0} \mathrm{CFU} / \mathrm{mL}$. L. cani, Leptospira canicola, $10^{6.0} \mathrm{CFU} / \mathrm{mL} ;$ S. aure, Staphylococus aureus, $10^{7.0} \mathrm{CFU} / \mathrm{mL}$.

** Strength of reaction as judged by eye: 3 , strong; 2 , medium; 1 , weak; 0.5 , very weak; 0 , negative.

Table 2. Sensitivity of rapid immunochromatographic test kits for canine distemper virus using a CD1901 strain belonging to the Asia 1 genotype

\begin{tabular}{cccccc}
\hline \multirow{2}{*}{ Company } & \multicolumn{5}{c}{ Viral titer of CD1901 strain } \\
\cline { 2 - 6 } & $5^{*}$ & 4 & 3 & 2 & 1 \\
\hline A & $3^{* *}$ & 2 & 1 & 0 & 0 \\
B & 1 & 0.5 & 0 & 0 & 0 \\
C & 3 & 2 & 1 & 0 & 0 \\
D & 2 & 1 & 0 & 0 & 0 \\
E & 3 & 1 & 0 & 0 & 0 \\
F & 3 & 2 & 1 & 0 & 0 \\
G & 2 & 1 & 0.5 & 0 & 0 \\
Mean \pm STD & $2.4 \pm 0.78$ & $1.4 \pm 0.62$ & $0.5 \pm 0.5$ & 0 & 0 \\
Sum & 17 & 9.5 & 3.5 & 0 & 0 \\
\hline
\end{tabular}

* $10^{5.0} \mathrm{TCID} 50 / \mathrm{mL}$.

** Strength of reaction as judged by eye: 3 , strong; 2 , medium; 1 , weak; 0.5 , very weak; 0 , negative. 
Table 3. Strength of reaction of the rapid immunochromatographic test kits applied with five canine distemper virus strains

\begin{tabular}{ccccccc}
\hline \multirow{2}{*}{ Company } & \multicolumn{5}{c}{ Canine distemper virus strains } & \multirow{2}{*}{ Sum } \\
\cline { 2 - 5 } & CD1901 & Lederle & Onderstepport & Rockborn & Synder Hill & \\
\hline A & 2 & 2 & 3 & 3 & 3 & 13 \\
B & 0.5 & 2 & 1 & 2 & 2 & 7.5 \\
C & 2 & 2 & 3 & 3 & 3 & 13 \\
D & 1 & 3 & 2 & 2 & 2 & 10 \\
E & 1 & 3 & 2 & 2 & 2 & 10 \\
F & 2 & 3 & 3 & 3 & 3 & 14 \\
G & 1 & 3 & 2 & 2 & 3 & 11 \\
Mean \pm STD & $1.36 \pm 0.63$ & $2.57 \pm 0.53$ & $2.28 \pm 0.76$ & $2.43 \pm 0.53$ & $2.57 \pm 0.53$ & $11.2 \pm 2.27$ \\
Sum & 9.5 & 18 & 16 & 17 & 18 & 78.5 \\
\hline
\end{tabular}

* Strength of reaction as judged by eye: 3 , strong; 2 , medium; 1 , weak; 0.5 , very weak; 0 , negative. CDVs were tested at a viral titer of $10^{4.0} \mathrm{TCID} 50 / \mathrm{mL}$.

the RICT kits were evaluated using serially 10-fold diluted Korean CDV isolate. The detection limits for the Korean CDV isolate (CD1901) ranged from $10^{3.0}$ to $10^{4.0} \mathrm{TCID} 50 / \mathrm{mL}$ (Table 2). Three kits detected CDV down to $10^{4.0} \mathrm{TCID} \mathrm{D}_{50} / \mathrm{mL}$ and four kits to $10^{3.0} \mathrm{TCID} \mathrm{D}_{50} / \mathrm{mL}$. All of the seven commercial RICT kits detected four CDV vaccine strains (Lederle, Onderstepoort, Rockborn, and Synder Hill) and one Korean CDV isolate (CD1901) (Table 3). The mean score to measure the detection strength of the kits ranged from 9.5 to 18 points. Lederle and Synder Hill strains had the highest average score (2.57) among five CDV stains. There was an average difference of 1.1 in scores between the CDV vaccine strains (average 2.46) and the Korean CDV isolate (average 1.36).

\section{Genetic analysis of $\mathrm{H}$ gene}

The $\mathrm{H}$ protein of CD1901 strain was compared with those of four CDV vaccine strains to determine how its genetic relationship. The CD1901 strain showed the highest amino acid homology (95.7\%) with Rockborn strain, but had relatively low homology (90.8\%) with Lederle strain (Fig. 1A). A phylogenetic tree was constructed based on the $\mathrm{H}$ genes of 29 CDV strains to better understand the genetic relationships of the CDV strains. As shown in Fig. 1B, CDVs were divided into six genotypes such as Asia 1, 2, Europe 1, 2, 3 and America, and the CD1901 strain belonged to Asia 1 genotype.

\section{DISCUSSION}

The CDV is one of important viruses that impact on puppies or unvaccinated dogs. It has gained attention recently, because CDVs belonging to Asia 1 and 2 genotypes have been reported in Korea (15). Thus, the evaluation of rapid diagnostic tool such as RICT is necessary to enhance the diagnostic coverage. In this study, cross-reactivity, sensitivity of seven commercial RICT kits were evaluated with dog core pathogens and recent Korean CDV isolate. Six viral pathogens and three bacteria were not detected using the seven kits; there was no cross-reactivity, likely due to use in each kit of a specific capture and detection antibody to CDV N or H protein. RICT kits without cross-reactivity have advantages over other diagnostic methods in that they are straightforward and rapid, and can be successfully used by both owners and veterinarians. Although RCIT kits did not detect limited nine dog pathogens except for CDV, its application remained limited because of large number of potential pathogens. Thus, cross-reactivity test with more various pathogens may be required to gain trust from consumers.

The detection limit of the RICT kits applied to five CDV strains was lower than the required standard of $10^{4.0} \mathrm{TCID}_{50} / \mathrm{mL}$. It is natural that the lower the detection limit, the more preferred by consumer. However, the detection limit of RICT kits was 


\begin{tabular}{|c|c|c|c|c|c|c|}
\hline & \multicolumn{6}{|c|}{ Homology of amino acid sequence among hemagglutinin proteins of CDV } \\
\hline & Strain & CD1901 & Lederle & Onderstepport & Rockborn & Synder Hill \\
\hline \multirow{5}{*}{ 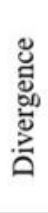 } & CD1901 & & 91.8 & 89.3 & 95.7 & 90.9 \\
\hline & Lederle & 8.2 & & 94.2 & 92.4 & 97.5 \\
\hline & Onderstepport & 10.7 & 5.8 & & 90.3 & 93.6 \\
\hline & Rockborn & 4.3 & 7.6 & 9.7 & & 92.1 \\
\hline & Synder Hill & 9.1 & 2.5 & 6.4 & 7.9 & \\
\hline
\end{tabular}

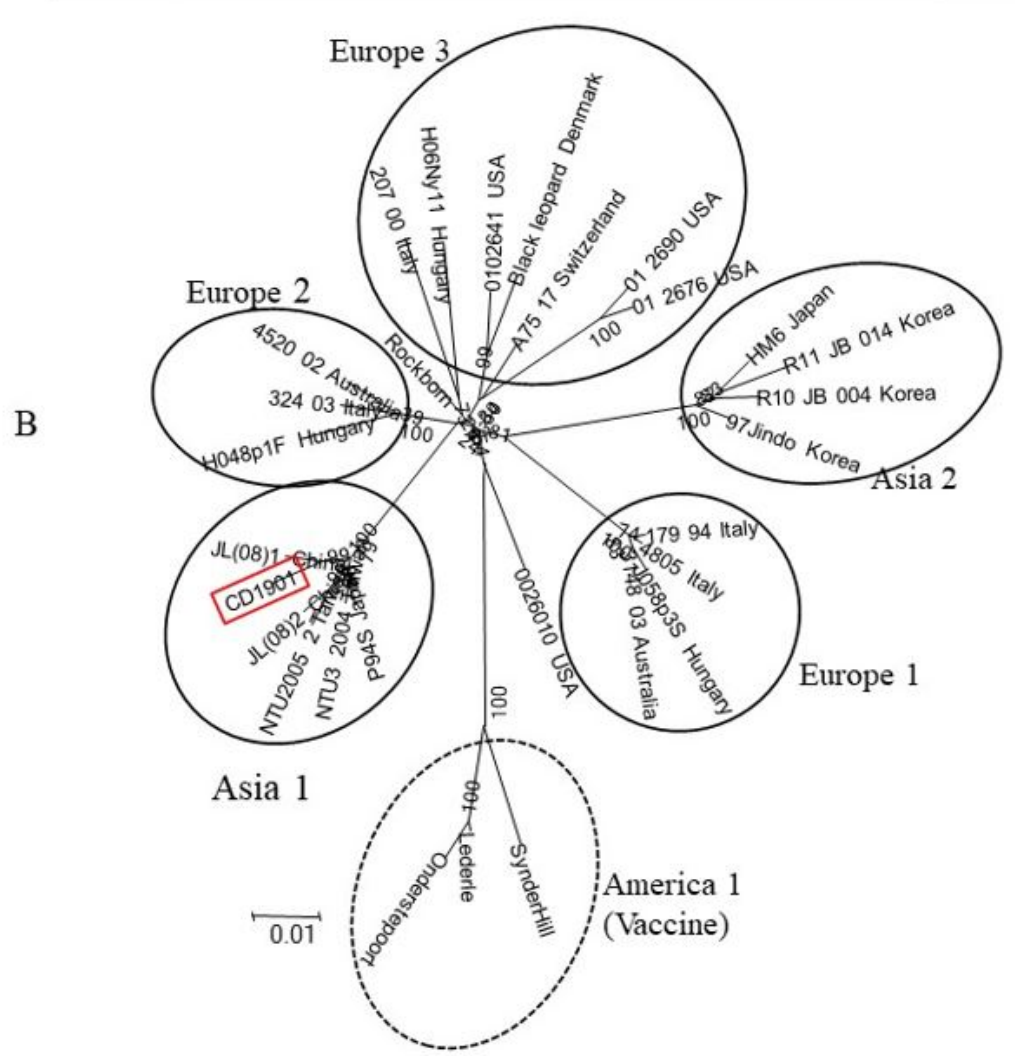

Fig. 1. Alignment of amino acid sequences of hemagglutinin $(H)$ protein among five canine distemper virus (CDV) strains (A) and phylogenetic tree based on the $\mathrm{H}$ gene of 29 CDV strains (B). CDV can be classified into six genotypes such as Asia 1 and 2, Europe 1, 2, and 3, and America 1. Three CDV vaccine strains belonging to America 1 are indicated by a dotted circle, but CD1901 strain to Asia 1 is indicated by box with a red line.

higher than that of nested RT-PCR or multiplex RT-PCR $\left(\sim 10^{0.7} \mathrm{TCID}_{50} / \mathrm{mL}\right)(16,17)$. In addition, the sensitivity of the RICT kits for a Korean CDV isolate of the Asia 1 genotype ranged from $10^{3.0}$ to $10^{4.0} \mathrm{TCID} 50 / \mathrm{mL}$. In principle, RICT and RT-PCR methods are different for antigen detection. In other words, RICT relies on the capture antibody attached to the gold conjugate, while RT-PCR test is a method of amplifying the target gene with specific primer sets. Despite the limited sensitivity of the kit, the sensitivity of the RICT kits needs to be improved using antibodies that can capture all CDV genotypes.

Analysis of CDV H gene responsible for attachment has been performed to find genetic variation among five CDV strains including Korean CDV strain. Homology of amino acid of the five $\mathrm{H}$ proteins revealed that the CD1901 strain had low homology ranging from 89.3 to $95.7 \%$ with CDV vaccine strains. As large differences in homology of $\mathrm{H}$ protein between the vaccine strain and field CDV may induce incomplete protection to dogs immunized with CDV vaccine belonging to America 1 genotype (3), this low homology may also cause low sensitivity in RICT kit. Furthermore, phylogenetic tree showed that CD1901 strain classified into Asia 1 genotype was genetically distinct from Lederle strain. Therefore, it is 
important to use specific antibodies that can capture various CDV genotypes in RICT kit. In this respect, it may be good if the CD1901 strain is used as antigen for the production of antibody in mice to select antibodies against $\mathrm{N}$ or $\mathrm{H}$ protein.

In conclusion, seven commercial RICT kits showed no cross-reactivity with other dog pathogens, and sensitivity ranging from $10^{3.0}$ to $10^{4.0} \mathrm{TCID}_{50} / \mathrm{mL}$ with various CDV strains. Therefore, Korean RICT kits could be useful for the rapid detection of CDV vaccine strains, but their sensitivity could be improved by the use of other antibodies to $\mathrm{N}$ or $\mathrm{H}$ proteins from CDV strains of the Asia 1 or 2 genotype.

\section{ACKNOWLEDGMENTS}

This study was supported financially by a grant (B-1543083-2019-21-01) from the Animal and Plant Quarantine Agency, Ministry of Agriculture, Food and Rural Affairs (MAFRA), Korea.

\section{REFERENCES}

1) Appel MJ, Summers BA. Pathogenicity of morbilliviruses for terrestrial carnivores. Vet Microbio/ 1995;44:187-91.

2) Kennedy JM, Earle JAP, Omar S, Abdullah H, Nielsen O, Roelke-Parker ME, et al. Canine and phocine distemper viruses: global spread and genetic basis of jumping species barriers. Viruses 2019;11:944.

3) Cha SY, Kim EJ, Kang M, Jang SH, Lee HB, Jang HK. Epidemiology of canine distemper virus in wild raccoon dogs (Nyctereutes procyonoides) from South Korea. Comp Immunol Microbiol Infect Dis 2012;35:497-504.

4) Bae CW, Lee JB, Park SY, Song CS, Lee NH, Seo KH, et al. Deduced sequences of the membrane fusion and attachment proteins of canine distemper viruses isolated from dogs and wild animals in Korea. Virus Genes 2013;47:56-65.

5) Li W, Cai C, Xue M, Xu G, Wang X, Zhang A, et al. Phylogenetic analysis of canine distemper viruses isolated from vaccinated dogs in Wuhan. J Vet Med Sci2018;80:1688-90.

6) Beineke A, Puff $C$, Seehusen $f$, Baumgärtner W. Pathogenesis and immunopathology of systemic and nervous canine distemper. Vet Immunol Imuunopatho/ 2009;127:1-18.

7) Deem SL, Spelman LH, Yates RA, Montali RJ. Canine distemper in terrestrial carnivores: a review. J Zoo Wildl Med 2000;31:441-51.

8) An DJ, Kim TY, Song DS, Kang BK, Park BK. An immunochromatography assay for rapid antemortem diagnosis of dogs suspected to have canine distemper. J Virol Methods 2008;147:244-9.

9) Latha D, Geetha M, Ramadass P, Narayanan RB. Evaluation of ELISA based on the conserved and functional middle region of nucleocapsid protein to detect distemper infection in dogs. Vet Microbio/2007:120:251-60.

10) Shin YJ, Cho KO, Cho HS, Kang SK, Kim HJ, Kim YH, et al. Comparison of one-step RT-PCR and a nested PCR for the detection of canine distemper virus in clinical samples. Aust Vet J2004;82:83-6.

11) Liu $Y$, Liu $C$, Liu W, Wu H, Ding $H, C a o ~ Y$, et al. Isolation and sequence analysis of the complete $H$ gene of canine distemper virus from domestic dogs in Henan Province, China. Arch Viro/2019:164:2153-8.

12) Gray LK, Crawford PC, Levy JK, Dubovi EJ. Comparison of two assays for detection of antibodies against canine parvovirus and canine distemper virus in dogs admitted to a Florida animal shelter. I Am Vet Med Assoc 2012:240:1084-7 
13) Eggerbauer E, de Benedictis P, Hoffmann B, Mettenliter TC, Schlottau K, Ngoepe EC, et al. Evaluation of six commercially available rapid immnochromatographic tests for the diagnosis of rabies in brain material. PloS Neg/ Trop Dis 2016:10:e0004776.

14) Lyoo KS, Yeom M, Kim J, Kim D, Ha G, Na W, et al. Development of rapid immunochromatographic strip test for the detection of porcine epidemic diarrhea virus. Vet Rec 2017;181:596.

15) Han Jl, Kang SY, Na KJ. Comparison of canine distemper viruses in domestic dogs and wild raccoon dogs in South Korea. Vet Rec 2010;167:828-30.

16) Fischer CD, Ikuta N, Canal CW, Makiejczuk A, Allgayer Mda C, Cardoso CH, et al. Detection and differentiation of field and vaccine strains of canine distemper virus using reverse transcription following by nested real time $P C R$ (RT-nqPCR) and RFLP analysis. J Virol Methods 2013;194:39-45.

17) Piewbang C, Rungsipipat A, Poovrawan $Y$, Techangamsuwan S. Development and application of multiplex PCR assays for detection of virus-induced respiratory disease complex in dogs. J Vet Med Sci 2017;78:1847-54. 